Article

\title{
Impact of Momentary Cessation Voltage Level in Inverter-Based Resources on Increasing the Short Circuit Current
}

\author{
Namki Choi ${ }^{\circledR}$, Bohyun Park, Hwanhee Cho ${ }^{\circledR}$ and Byongjun Lee * \\ School of Electrical Engineering, Anam Campus, Korea University, 145 Anam-ro, Seongbuk-gu, Seoul 02841, \\ Korea; fleminglhr@korea.ac.kr (N.C.); wind833@korea.ac.kr (B.P.); whee88@korea.ac.kr (H.C.) \\ * Correspondence: leeb@korea.ac.kr; Tel.: +82-10-9245-3242
}

Received: 19 January 2019; Accepted: 19 February 2019; Published: 21 February 2019

\begin{abstract}
This study analyzed the impact of varying the momentary cessation (MC) voltage level on the short circuit current of inverter-based resources (IBRs). To analyze the impact of the IBR MC function on the short circuit current, this paper proposes an advanced IBR model for fault current calculation to reflect its fault characteristics and a scheme for analyzing the influence of MC on the short circuit current. Based on the proposed methods, the authors conducted case studies using planning data from the Korea Electric Power Corporation (KEPCO). The influence of MC was investigated on the IBRs located at the southwest side of the KEPCO systems by screening the fault currents while varying the MC voltage. This paper demonstrates that the minimum MC voltage level needed for the fault current not to exceed the circuit breaker (CB) capacity can be proposed through analyzing the impact of MC voltage level on the short circuit current. The test results based on the proposed scheme showed that the short circuit current to power systems could not violate $\mathrm{CB}$ capacity if IBRs adjusted the MC voltage level higher than the lowest MC voltage level.
\end{abstract}

Keywords: Momentary cessation (MC); inverter-based resources (IBRs); fault current; grid integration of renewable energy systems; control strategy of inverters

\section{Introduction}

The fast expansion of inverter-based resources (IBRs) has created a new variation in power systems. The characteristics of IBRs (e.g., Wind Turbine Generators and solar Photovoltaics), which differ from those of conventional synchronous generators, have different control, operation, and protection systems and fault current contributions in power systems [1-3]. In the results of References [4-6], IBRs produced a smaller amount of fault current to a maximum of $1.2 \mathrm{pu}$ of nominal current, compared to conventional synchronous generators $(10 \mathrm{pu})$. The short circuit current to power systems is reduced as the conventional synchronous generators are replaced by IBRs [4]. However, the short circuit current at the system buses, which are remote from conventional synchronous generators and closer to many IBRs, may be larger. With IBR expansion, this small fault current, if aggregated by several IBRs, can significantly adjust the short circuit current, thereby resulting in the malfunction of protective systems [7-9].

Several factors affect the fault current contribution of IBRs [9]. One of these is momentary cessation (MC), which is a control strategy applicable only to IBRs. In accordance with a standard [10], MC is a ride-through mode for IBR response to abnormal voltage, as seen in Table 1. In the case of system disturbance, the active current is limited to zero if the IBR output terminal voltage is lower than the specified $M C$ voltage $\left(V_{M C}\right)$ [10]. An IBR in MC mode produces a zero-fault current contribution, as the current is limited $[4,10]$. Consequently, an IBR provides a fault current contribution when not in 
MC mode. Hence, the control characteristics of the inverter, such as MC, can influence the IBR fault current contribution.

Table 1. Inverter-based resource (IBR) response to abnormal voltages [10].

\begin{tabular}{ccc}
\hline Operation Mode & Voltage (Pu of Nominal Voltage) & Default Clearing Time(s) \\
\hline May ride through or trip & $1.20<\mathrm{V}$ & 0.16 \\
Momentary cessation ${ }^{1}$ & $1.10<\mathrm{V} \leq 1.20$ & 13.0 \\
Continuous operation $^{\text {Mandatory operation }}$ & $0.88 \leq \mathrm{V} \leq 1.10$ & - \\
Momentary cessation $^{1}$ & $0.50 \leq \mathrm{V}<0.88$ & 21.0 \\
\hline
\end{tabular}

${ }^{1}$ Temporarily cease to energize an electrical power system (EPS), while connected to the area EPS, in response to a disturbance of the applicable voltages or the system frequency, with the capability of immediately restoring the output of operation when the applicable voltages and the system frequency return within defined ranges. The voltage threshold between mandatory operations and momentary operations may be changed by mutual agreement between the area EPS operator and the distributed energy resources (DER) operator, e.g., to allow the DER to provide dynamic voltage support below 0.5 p.u.

There have been several unintended solar generation loss events observed due to $\mathrm{MC}$ operation. One report from the North American Electric Reliability Corporation (NERC) analyzed an approximately 1200-MW generation loss of solar photovoltaics resources at bulk power systems (BPS) as a result of transmission fault events [11]. A cause of the generation loss $(\approx 450 \mathrm{MW})$ was the inverter MC mode since system voltage was reached to the low voltage ride-through of the inverters. In the event, most installed inverters set the MC operation ranges for voltages of lower than $0.9 \mathrm{pu}$ or higher than $1.1 \mathrm{pu}$. Therefore, the majority of solar PVs could enter the MC mode due to the wide MC operation ranges, and the unexpected generation loss occurred. Another report from NERC raised a concern, where a 900-MW generation loss of solar PV resources was caused by inverter MC operation as a result of two transmission systems near the Serrano substation east of Los Angeles [12]. The inverters had still used MC operation for the same voltage ranges $(\mathrm{V}<0.9 \mathrm{pu}, \mathrm{V}>1.1 \mathrm{pu})$. The unintended generation loss due to $\mathrm{MC}$ resulted in the instability of the power systems. NERC recommended the usage of low-MC voltage with IBRs to solve this problem and improve power system stability. Based on standards and reports [10-12], the MC function can be applied not only to IBR distribution systems but also to IBR transmission systems.

Reducing the MC voltage is a plausible option to maintain power system stability, as fewer IBRs would enter MC mode and more IBRs would restore power generation after faulty elements are eliminated. However, a large number of IBRs can contribute short circuit currents to the grid with a lower MC voltage. With this, an increase in the IBR fault current contributions may result in the malfunction of existing grid protection facilities [6,9]. Hence, in view of fault currents, a minimum MC voltage level needs to be established.

Short circuit studies are implemented to calculate fault current to power systems for determining circuit breaker (CB) capacity. Generally, the traditional calculation of fault current to power systems is to use the system impedance matrix. This traditional method is suitable for short circuit studies on conventional power systems without IBRs. For grids with IBRs, the method should be modified to consider IBR fault current contributions to power systems, since IBR fault responses are different from conventional synchronous generators. An analysis of the modified method is discussed in Reference [13]. However, for networks with IBRs, adapting an impedance matrix to short circuit calculations is complicated, since determining the impedance of power electronics is difficult [1].

In this paper, the impact of MC voltage on IBR short circuit currents is presented. An improved IBR model was established to reflect its fault current characteristics in fault calculations. The influence of MC voltage on the IBR fault current was analyzed in comparison to fault currents at buses, which exceeded circuit breaker capacity with a varying MC voltage. The lowest MC voltage of an IBR is suggested to avoid exceeding CB capacity. 


\section{Materials and Methods}

\subsection{Fault Current Contributions of an IBR in MC}

IBRs (e.g., a wind turbine generator type IV, a solar PV) are connected to the grid through power electronics (e.g., an inverter), as shown in Figure 1 [5,6]. Sources with converters produce Direct Current (DC) power from IBR sources (e.g., turbines or PVs). The DC voltage is held by DC link capacity to be constant and is converted to three-phase Alternating Current (AC) voltage through an inverter. Inverter control schemes are implemented for constant power output to grids. Generally, there are voltage and current control schemes to regulate power output in industries [6,9]. A voltage control scheme produces a higher initial current spike during a fault. On the other hand, a current control scheme produces a much slower response back to a steady state during a fault. Hence, inverter control schemes with a current limit function protect semiconductor switches from over-current due to the low thermal inertia $[4,6,14]$.

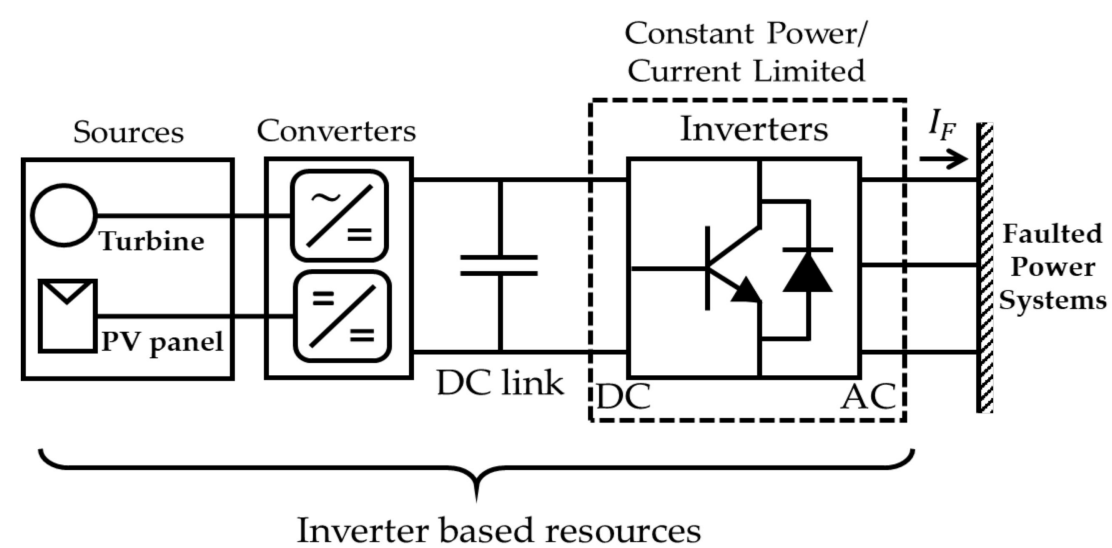

Figure 1. A representation of the IBR main components producing a limited fault current.

With a current limit function, IBR has a fault performance different from a conventional synchronous generator. From a fault response analysis $[4,6,14]$, the fault performance from an IBR can be divided into two periods:

Period 1. Period 1 is the approximate time ( 2 cycles) between fault occurrence and fault detection. The IBR produces a higher output current to sustain the power constant at a lower-than-rated terminal voltage. The magnitude of the output current can usually be as high as 2.5 pu during this period. The actual value of the output current is determined by several factors, such as wind conditions, voltage level, and the pre-set point of active and reactive current for normal operation;

Period 2. After period 1, the magnitude of output current becomes lower. The low magnitude fault current is adjusted by a pre-set fault ride-through mode (FRT mode). The IBR fault current $\left(I_{F}\right)$ is limited to a maximum of 1.2 pu of the nominal current if terminal voltage is higher than MC voltage. In other words, the IBR enters MC mode in order to block the fault current, as terminal voltage is lower than MC voltage.

In study [5], the IBR fault current contribution was relatively smaller than that of conventional synchronous generators (10 pu), and therefore considered negligible. However, with a large number of IBRs connected to the power systems and fewer conventional synchronous generators connected to the grid, the IBR short circuit currents were significantly considered. Even with their minimal short circuit current to power systems, due to rapid IBR expansion, significant IBR fault current contributions may result in the short circuit current exceeding CB capacity at buses far from the conventional synchronous generators [14]. 
The MC voltage determines whether IBRs could contribute fault current to the grids. Control parameters of IBRs, such as MC voltage level, can affect their short circuit current contribution. To precisely analyze the influence of a varying MC voltage on the short circuit current, IBR fault current characteristics should be considered in the model. With this, the short circuit current to the power systems can be analyzed with a varying MC voltage level. A minimum MC voltage is proposed to avoid exceeding the existing $\mathrm{CB}$ capacity.

\subsection{IBR Model for Short Circuit Current Calculation}

Numerous papers have discussed IBR models and fault responses in electromagnetic transients including DC (EMTDC) for short time durations [15-20]. These options are applicable for analysis of small power systems. However, in this paper, the simulation was based on a large power system, and the short circuit current was calculated by PSS/E software (Power System Simulator for Engineers) in a steady state. In PSS/E, automatic sequencing short circuit calculation (ASCC) and breaker duty (BKDY) are normally used to calculate the fault current. The ASCC calculates only the symmetrical components of the fault current and requires additional values for the calculation of the asymmetrical components. The flat option can be used where generators are modeled as an internal voltage source with a magnitude of $1 \mathrm{pu}$ and a phase angle of $0^{\circ}$. On the other hand, BKDY calculates both the symmetrical and asymmetrical components of the fault current. It is based on equations derived from time-dependent dynamic models of generators. In Korea, the fault current is normally calculated using ASCC. Hence, ASCC was used in the fault current calculation in this paper. However, as ASCC can only model a conventional synchronous generator as a voltage source with internal impedance, the IBR model was simplified as an inverter-based resource connected to a transmission system for fault current analysis in a steady state.

The IBR was modeled as a constant current source, as shown in Figure 2a, since it produces a fault current of $1.2 \mathrm{pu}$ of the nominal current. The subtransient impedance, $X_{d^{\prime \prime}}$, is typically applied to determine the short circuit current as a generator internal impedance when responses are determined by most transmission system relays [6]. In PSS/E, it is used, along with the generator internal voltage, as input data for fault calculation. Figure $2 a$ can be replaced with Figure $2 b$ for IBR fault current calculation.

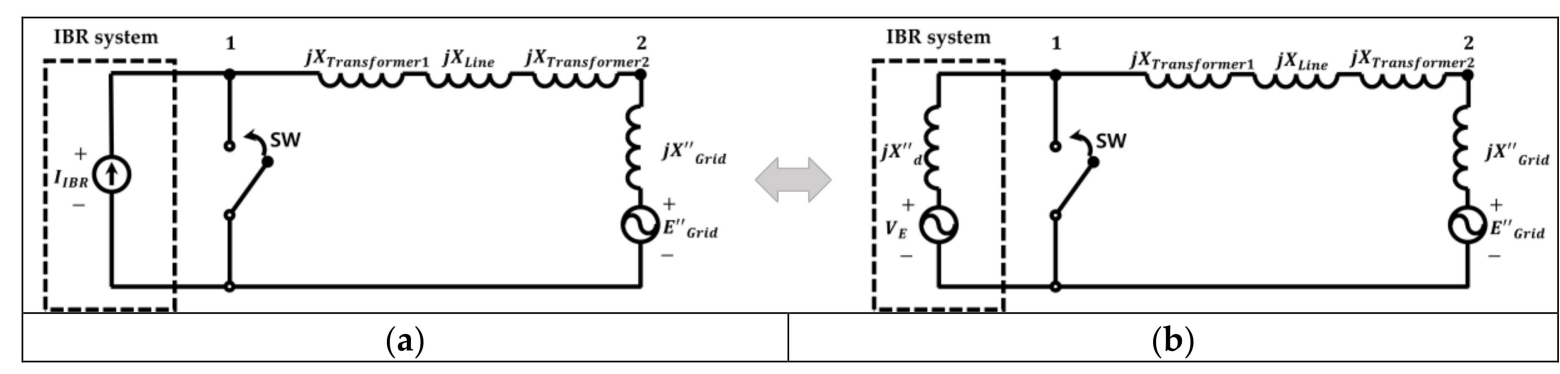

Figure 2. Modeling of the equivalent IBR circuit after the fault: (a) IBR model represented as a constant current source; (b) Replaced IBR model for fault calculation.

From short circuit current calculation research [16], several assumptions were made for the simplification of the IBR fault current calculation. The internal generator voltage $\left(V_{E}\right)$ was assumed to be $1.0 \mathrm{pu}$, and the faulted bus voltage $\left(V_{F}\right)$ was assumed to be zero. This calculation is shown by the following:

$$
\mathrm{I}_{\mathrm{f}, \mathrm{IBR}}=\frac{\mathrm{V}_{\mathrm{E}}-\mathrm{V}_{\mathrm{F}}}{\mathrm{X}_{\mathrm{d}^{\prime \prime}}}=\frac{1-0}{\mathrm{X}_{\mathrm{d}^{\prime \prime}}}=\frac{1}{\mathrm{X}_{\mathrm{d}^{\prime \prime}}},
$$

where $I_{f, I B R}$ is the IBR limited fault current, $V_{E}$ is the internal generator voltage, $V_{F}$ is the faulted bus voltage, and $X_{d}{ }^{\prime \prime}$ is the subtransient impedance of the generator.

Equation (1) shows the IBR current limit function represented by the voltage source and subtransient impedance of the generator. Wind turbine generator type IV and solar photovoltaics have 
a subtransient impedance of $0.833 \mathrm{pu}$, since the fault current for both IBRs is limited to $1.2 \mathrm{pu}$ of the nominal current. The IBR was connected to the transmission system via a transformer, which could be represented by the impedance of the fault current calculation in ASCC. The transformer impedance was reflected in the IBR model by connecting the subtransient impedance in a series. A 0.3-pu value for transformer impedance is typically used for transformers from $22.9 \mathrm{kV}$ to $154 \mathrm{kV}$ in Korean power systems. A 1.133-pu value for advanced subtransient impedance was added between the original subtransient and the transformer impedance, as shown in Figure 3.
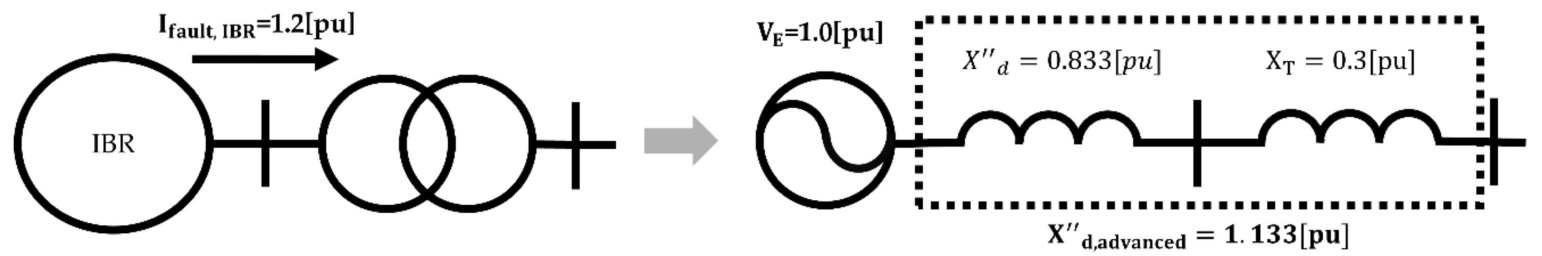

Figure 3. Modeling of the voltage source and subtransient impedance to represent an IBR with a transformer.

\subsection{Proposed Scheme for Identifying the Impact of MC Voltage Level on Short Circuit Current}

As discussed in Section 2.2, the subtransient impedance of IBRs should be updated to reflect the fault current characteristics of IBRs. In Figure 4, the proposed scheme, by using the updated IBR model, can analyze the impact of MC voltage level on short circuit current to power systems. The advantage of the proposed scheme is the ability to determine the minimum MC voltage level for the short circuit current not to exceed CB capacity. This minimum MC voltage level can notify a power systems planner that the fault current to the power systems may exceed CB capacity if IBRs set their MC voltage levels to lower than the minimum MC voltage level.

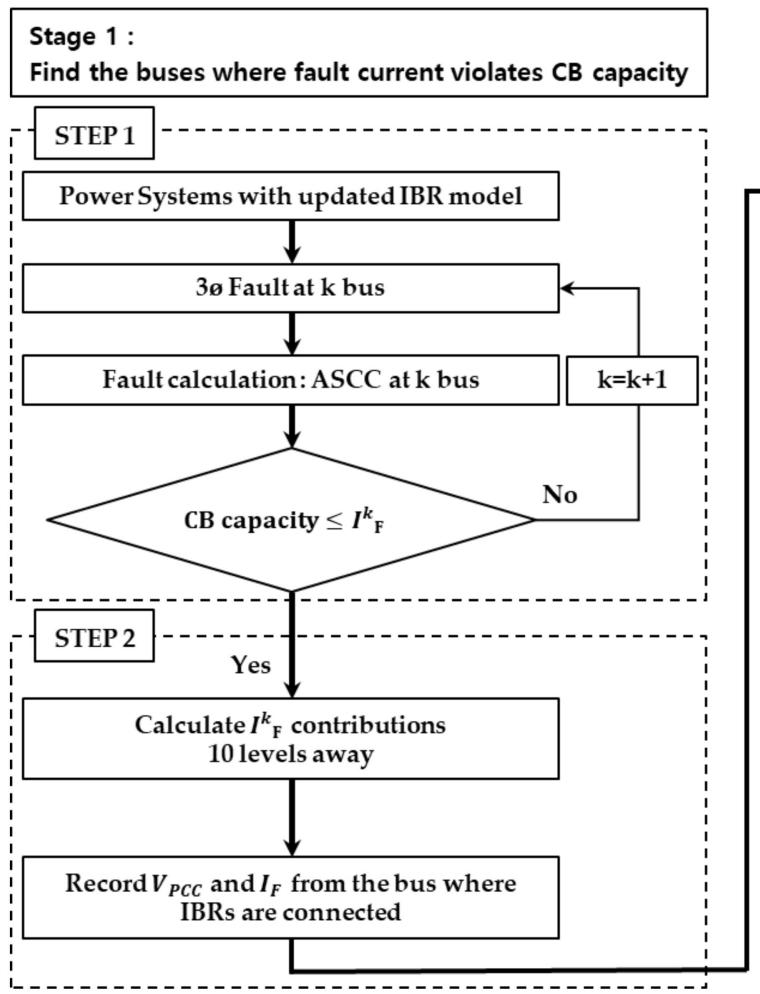

Stage 2:

Determine minimum momentary cessation voltage level

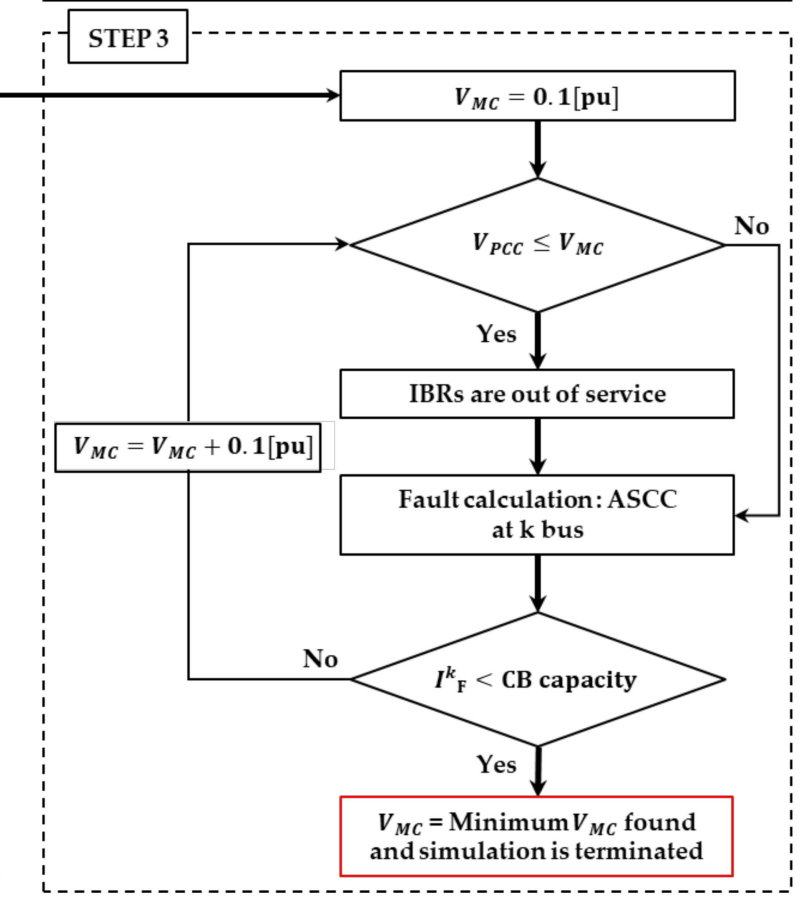

Figure 4. Schemes to analyze the influence of momentary cessation (MC) voltage levels on short circuit levels. 
The proposed scheme can be divided into two stages, as seen in Figure 4. Stage 1 is to select system buses where the fault current exceeds CB capacity. Next, stage 2 is to figure out the minimum MC voltage level. These stages can be separated into three steps, as follows:

Step 1. The input is the power system with the updated IBR model in this step. A 3-phase balanced fault is implemented to consider the most severe faults in the simulation, since a 3-phase balanced fault is the most serious fault in a transmission system. The short circuit current at $k$ bus is calculated by ASCC. This step 1 is repeated until the short circuit current calculated by ASCC exceeds CB capacity;

Step 2. For example, $k$ bus is found in step 1 due to the short circuit current violating CB capacity. $I_{F}^{k}$ is the short circuit current at $k$ bus as an output of step 1. In step 2, the IBR fault currents, which contribute to $I_{F}^{k}$, are calculated by ASCC. These IBR fault current contributions are the fault currents from the bus where IBRs are connected within 10 levels away from the faulted location while the fault occurs. From the calculated IBR fault current contributions, the voltage and fault current at the point of common coupling (PCC) are recorded;

Step 3. The MC voltage is set to 0.1 pu initially. The PCC voltage from step 2 is compared to the MC voltage to determine which IBRs will be in service. The IBRs are in service since the PCC voltage is greater than the MC voltage level. The on/off status of IBRs are determined by comparison between PCC voltage and MC voltage and are updated with the input data of step 1. With the updated input data, the short circuit current calculation is done by ASCC at the same faulted location. This step is repeated as $\mathrm{MC}$ voltage level increases by $0.1 \mathrm{pu}$ until the short circuit current is lower than $\mathrm{CB}$ capacity. From this step, the minimum MC voltage level can be determined, as the short circuit current is less than CB capacity.

\subsection{Implementation in PSS/E}

The data of power systems can be simply modified in a *.raw file in PSS/E. The *.raw file consists of 23 steady-state parameters to model the power systems, such as bus data, plant data, machine data, load data, branch data, and transformer data. Machine data in a *.raw file have generator service status, active and reactive power generation, a machine base, machine impedance, etc. The machine data should be updated to reflect the IBR fault current characteristics. The subtransient impedance, which was calculated in Equation (1), is used as the IBR subtransient impedance. Hence, IBRs are modeled as a constant current source during fault analysis.

As discussed in a previous section, in PSS/E, short circuit calculation is done by ASCC. The flat option in ASCC is used as a system condition for short circuit study. The flat condition is that generators are modeled as an internal voltage source with a magnitude of $1 \mathrm{pu}$ and a phase angle of 0 degrees. This condition is equal to the assumption made to calculate IBR subtransient impedance. With this condition, the fault current at the faulted location can be calculated by ASCC. In addition, ASCC can calculate fault current contributions 10 levels away from the faulted location. This can be implemented by modifying the output option of ASCC.

\subsection{Description of Case Study in KEPCO Systems}

The simulation was conducted in KEPCO systems in 2030. The short circuit current was compared between the base case (systems with no IBRs) and the IBR case (systems with IBRs). The systems data are shown in Table A1. The base case only utilized conventional synchronous generators without IBRs. In the IBR case, the IBR units were connected to the power system and distributed to individual buses as anticipated in the year 2030 in a future grid [21].

In Korea, the typical CB capacity is $31.5 \mathrm{kA}$ for a $154-\mathrm{kV}$ transmission system. This capacity was used as an indicative level to determine the influence of the $\mathrm{MC}$ voltage in increasing the short circuit current. A change in the fault current was observed when the MC voltage was varied. This was due to the number of IBRs in the grid. The lowest MC voltage level was obtained by locating a point where the fault current did not exceed CB capacity. 
The buses where the fault current exceeded the CB capacity were determined. This demonstrated the increase in the fault current caused by IBRs. The fault current at each bus obtained was then analyzed by calculating the short circuit current contribution. The PCC voltage and IBR fault current contributions were used to investigate the influence of the MC voltage. The IBR was simulated to be out-of-service when the PCC voltage was lower than the MC voltage. This demonstrated variations by the IBR fault current contributions on the short circuit current of the power systems while varying the MC voltage level.

\section{Results}

The schemes of the influence of the MC voltage on the short circuit current were demonstrated in KEPCO systems. The summary of step 1 in the proposed scheme is shown in Table 2. $\Delta I_{F \text {, Inc }}$ is the increase in the fault current from the difference between the base case and the IBR case. There were 18 buses that exceeded CB capacity, since the IBRs penetrated to Honam (southwest side of Korea). The configuration of the $154-\mathrm{kV}$ and $345-\mathrm{kV}$ transmission systems in Honam is shown in Figure 5 . The four buses with the largest short circuit currents were placed far from the conventional synchronous generators. This was due to their short circuit currents depending more on the IBR fault current contributions rather than the conventional synchronous generators. On the other hand, the five buses with the lowest fault currents were placed near the conventional synchronous generators. The IBR penetration had less impact on these five buses. Singangin1, with the largest increase in fault currents, was used as the example for the next simulation to observe the MC voltage level impact on the short circuit current.

Table 2. Buses that exceeded circuit breaker (CB) capacity sorted by the increase in fault current in descending order.

\begin{tabular}{ccc}
\hline Bus Name & $\boldsymbol{I}_{\boldsymbol{F}, \text { Base_case }}[A]$ & $\Delta \boldsymbol{I}_{\boldsymbol{F}, \boldsymbol{I n c}}[\boldsymbol{A}]$ \\
\hline Singangjin1 & 29005.2 & 13550.0 \\
Naju & 25229.7 & 9749.1 \\
Gangjin & 22742.6 & 9529.5 \\
Sinhwasun1 & 30371.1 & 8923.9 \\
Songjeong & 28844.3 & 5847.8 \\
Pyeongdong & 28001.8 & 5827.9 \\
Deongnim & 27971.7 & 5249.2 \\
Bia & 30907.7 & 5062.8 \\
Woljeon & 26505.2 & 5051.6 \\
Suwan & 26944.8 & 4705.1 \\
Cheomdan & 27968.6 & 4090.2 \\
Jeongju\#2 & 30446.7 & 3610.5 \\
Jeongju\#1 & 30805.9 & 3129.0 \\
Taepyeong & 30836.6 & 1773.1 \\
Jeonju & 31189.3 & 1754.7 \\
Seogok & 30361.5 & 1667.2 \\
Yeongdeung & 31300.8 & 1491.1 \\
Sepung\#2 & 31058.5 & 1097.8 \\
\hline
\end{tabular}

Figure 6 represents the IBR fault currents and PCC voltage of the buses where an IBR was connected when a three-phase balanced fault occurred at Shingangjin1. The stick graph illustrates the cumulative fault current, and the line graph corresponds to the PCC voltage. The buses were sorted by the PCC voltage value in descending order from the left to the right of the graph in Figure 6 . On the left side, the bus was placed far from Shingangjin1. The fault current accumulated from a point far from Shingangjin1. The left side of the red dot on the PCC voltage graph shows the IBR supply fault currents in Figure 6. In other words, the IBRs located at the left side of the red dot were not in MC mode, since their PCC voltages were greater than their MC voltages. The other side of the red dot represents IBRs that had no contribution to the fault current, since the PCC voltage was less 
than the MC voltage. As a result, these IBRs were in MC mode, thereby blocking the current flow. The fault current from the IBRs was $12.2 \mathrm{kA}$ when the MC voltage level was $0.5 \mathrm{pu}$, as proposed by the IEEE1547-2018 in Figure 6a. The voltage maintenance range was typically $\pm 10 \%$ of the $154-\mathrm{kV}$ transmission systems. Considering this, the fault current contribution from IBRs was $1.75 \mathrm{kA}$ when the MC voltage was $0.9 \mathrm{pu}$. As stated earlier and as seen in Figure 6, a low MC voltage level resulted in more IBR fault current contributions.

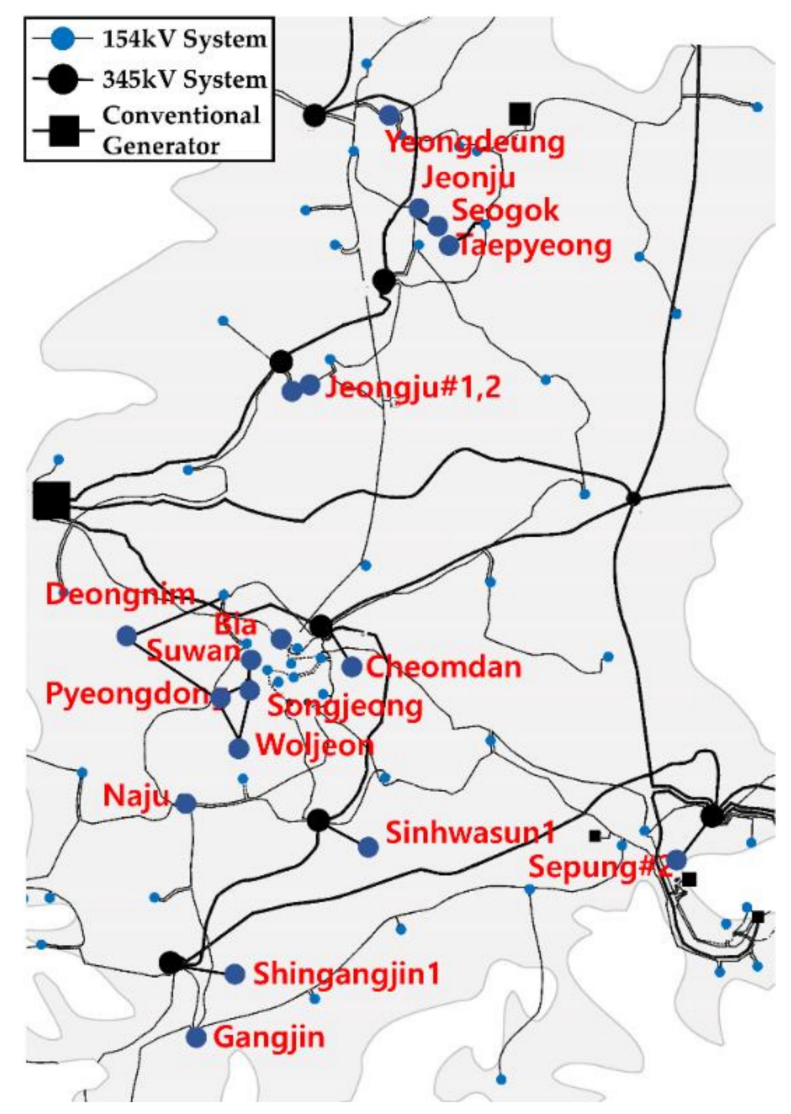

Figure 5. The system configuration of the Korea Electric Power Corporation (KEPCO) system where fault currents were over the CB capacity.

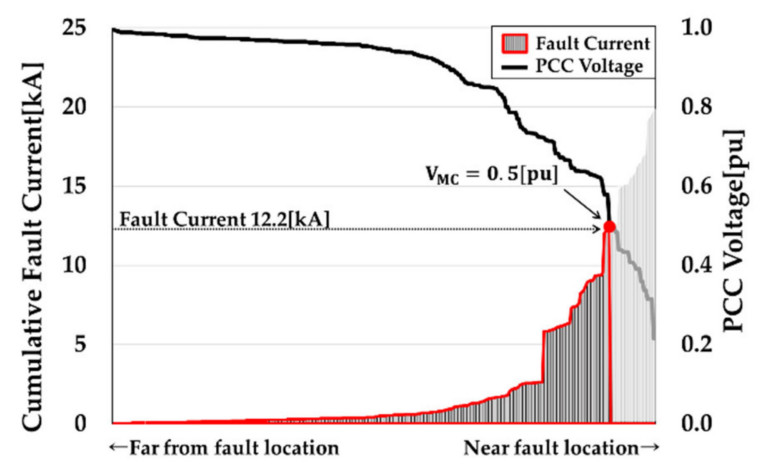

(a)

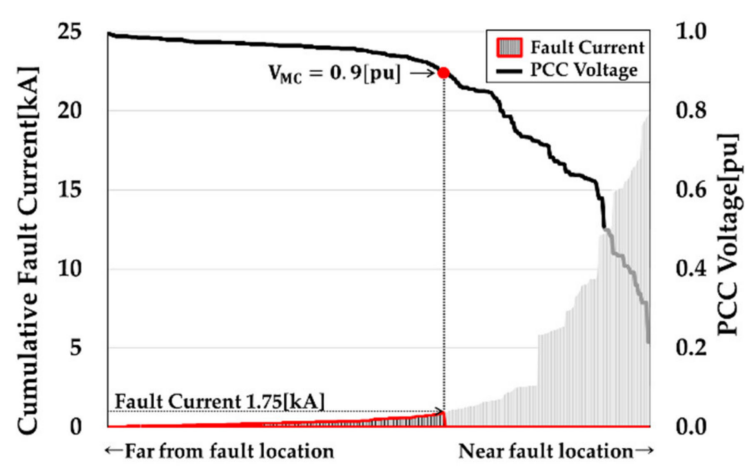

(b)

Figure 6. Point of common coupling (PCC) voltage and cumulative fault currents from IBRs within (n-10) levels from Shingangjin1: (a) $V_{M C}=0.5 p u$; and (b) $V_{M C}=0.9 p u$.

The short circuit current at Shingangin1 with respect to the MC voltage level is shown in Figure 7a as a black plot. The red line in Figure 7a represents the typical CB capacity of $31.5 \mathrm{kA}$ for a $154-\mathrm{kV}$ 
transmission system. The black line intersected with the red line when $\mathrm{MC}$ voltage was between $0.7 \mathrm{pu}$ and $0.8 \mathrm{pu}$. The short circuit current at Shingangjin1 was measured to be $29.3 \mathrm{kA}$ when the MC voltage was $0.8 \mathrm{pu}$. This increased to $32.8 \mathrm{kA}$ when the $\mathrm{MC}$ voltage decreased to $0.7 \mathrm{pu}$. The increase in the short circuit current was due to the increase in IBR fault currents to $4.23 \mathrm{kA}$, as shown in Figure $7 \mathrm{~b}$, when the MC voltage level was reduced to $0.7 \mathrm{pu}$. This demonstrates the impact of varying the MC voltage on the short circuit current of the power systems. The fault current at Shingangjin1 was lower than the $\mathrm{CB}$ capacity when the MC voltage level was $0.8 \mathrm{pu}$. Hence, this was set as the lowest $\mathrm{MC}$ voltage level for the fault current so as not to exceed the CB capacity.

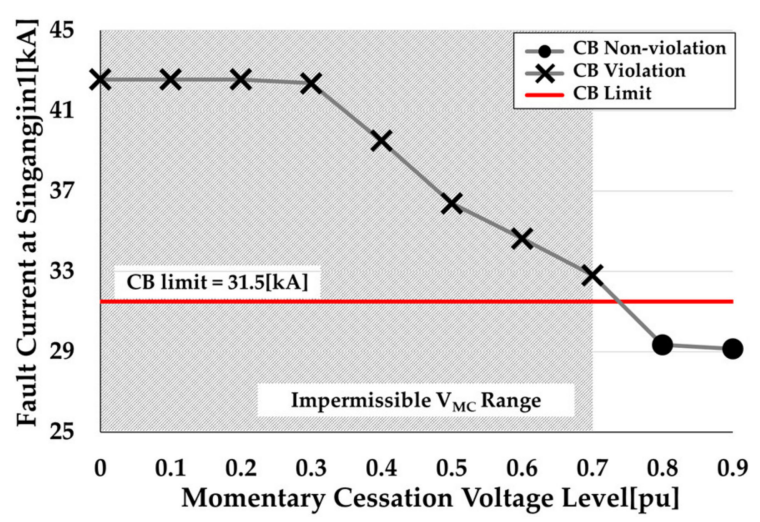

(a)

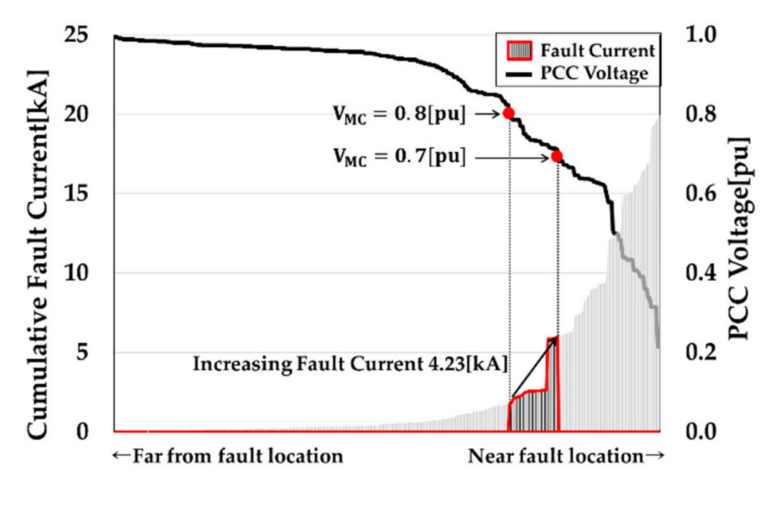

(b)

Figure 7. (a) Relationship between IBR MC voltage and fault current at Shingangjin1 with the CB capacity limit, and (b) cumulative IBR fault currents and PCC voltage levels between MC voltage values of $0.7 \mathrm{pu}$ and $0.8 \mathrm{pu}$.

In Figure 8a, the proposed scheme was applied to 18 buses that exceeded the CB capacity, including Shingangjin1. The fault current at each faulted location became lower as MC voltage level increased, which was similar to Figure 7a. However, each bus had a different point where its fault current exceeded CB capacity. In addition, the decrease in fault current at each bus was different, as can be seen in the gradient of the fault current lines in Figure 8a. This change in fault current was related to the number of IBRs in MC mode in Figure 8b. The number of IBRs in MC mode represented that the IBR fault current contribution depended on the MC voltage level. As MC voltage level was higher, a larger number of IBRs entered MC mode. For instance, at an MC voltage level of $0.9 \mathrm{pu}$, the decrease in the fault current at faulted Shingangjin1 was larger than Sepung\#2, since a larger number of IBRs entered MC mode. From this observation, the fault current to the power systems could be reduced as MC voltage level increased due to a lower IBR fault current contribution.

The fault current was reduced to lower-than-CB capacity at the specific MC voltage in Figure 8a. This specific MC voltage was the lowest MC voltage for fault currents not violating CB capacity. Figure 9 presents the minimum IBR MC voltage at each bus when a three-phase balanced fault occurred. The fault current exceeded the $\mathrm{CB}$ capacity when the IBR MC voltage was set lower than the minimum MC voltage. In other words, $66 \%$ of the 18 buses exceeded the CB capacity, as the MC voltage was set to $0.5 \mathrm{pu}$, as proposed by standards [10]. According to the standard in Reference [10] and other reports [11,12], from the perspective of power systems stability, the IBR MC voltage level should be lower. However, a lower MC voltage level may cause IBR fault current contributions to be increased. It is obvious that the system stability had higher priorities to consider than the fault current. Hence, fault analysis should be considered if IBR MC voltage is made lower for stability. From the fault current point of view, the minimum MC voltage value in Figure 9 can be a reference for the minimum MC voltage. 


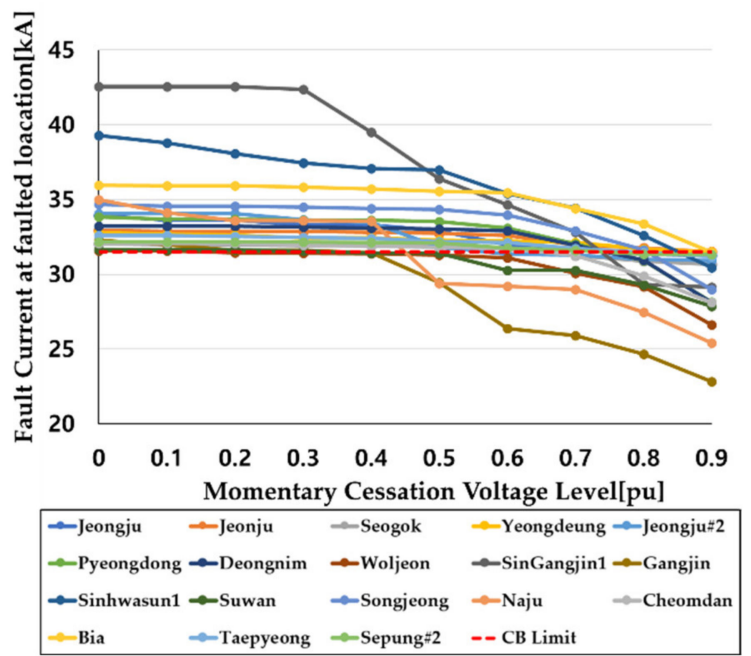

(a)

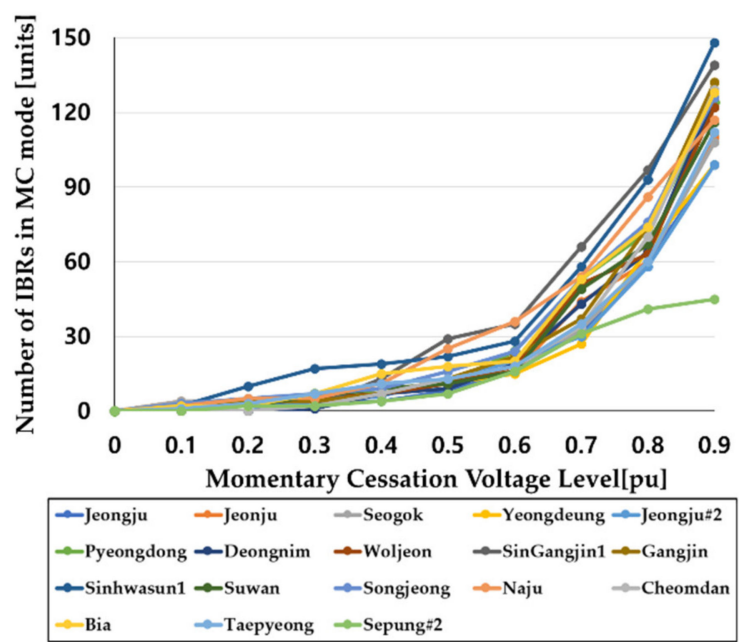

(b)

Figure 8. (a) Relationship between IBR MC voltage and fault current at each faulted location for exceeding the CB capacity, and (b) the number of IBRs in MC mode at each faulted location for varying IBR MC voltage.

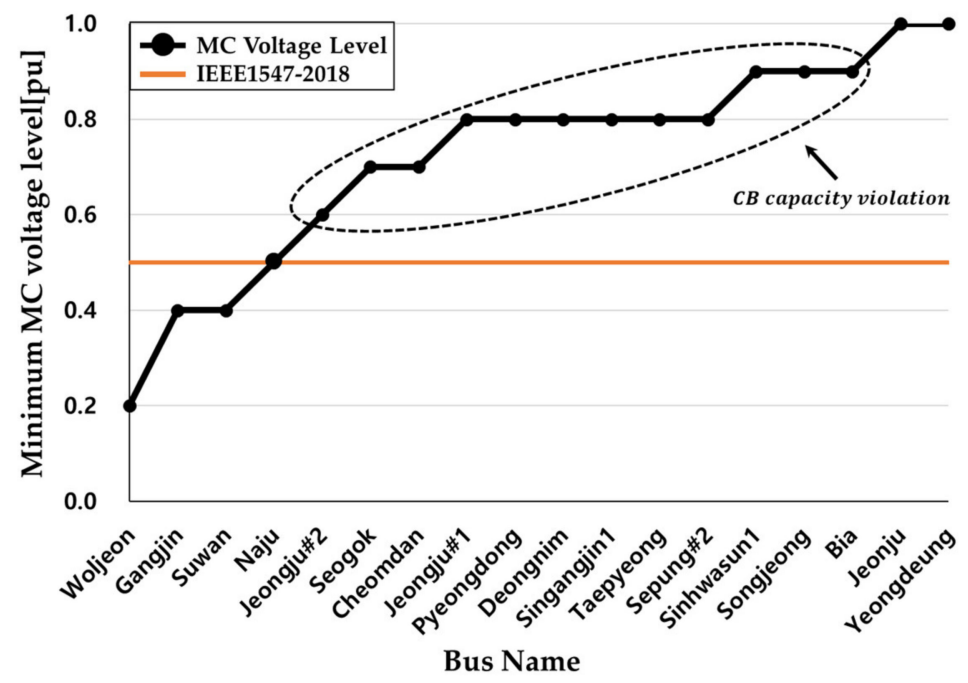

Figure 9. The minimum MC voltage level at each bus that did not exceed CB capacity, with a MC voltage of $0.5 \mathrm{pu}$, as proposed by IEEE1547-2018.

\section{Conclusions}

This paper demonstrated the impact of IBR MC voltage in increasing the short circuit current. The 18 buses had different minimum IBR MC voltage levels, and the decrease in fault current at each bus differed as MC voltage level was increased due to the topology of systems. The fault current was steeply decreased if the faulted location was electrically near the many IBRs and far from conventional synchronous generators. In other words, the impact of IBR MC voltage level on fault current was higher since the IBRs contributed more to fault current than conventional synchronous generators did. Some buses had a minimum IBR MC voltage that was higher than the 0.5 pu proposed by IEEE1547-2018. For these buses, the fault current might have exceeded the CB limit if IBR MC voltage was set to $0.5 \mathrm{pu}$. Hence, CB capacity should not need to be replaced if IBR MC voltage is set to the minimum MC voltage. From the perspective of fault currents, this minimum MC voltage can be used as the lowest boundary for setting IBR MC voltage. 
Two methods were used in this paper. First, an IBR model was developed to reflect its characteristics in fault analysis. This model used the fault analysis method of conventional synchronous generators, which represented the IBR in the analysis. Second, the proposed scheme provided the IBR fault current contributions while varying the MC voltage. This evaluated the influence of the MC voltage in increasing the short circuit current in power systems. Test results based on KEPCO systems showed that the proposed method accurately represented the influence of the MC voltage level on the short circuit current. The minimum MC voltage level needed for the fault current not to exceed the $\mathrm{CB}$ capacity was also determined. Consequently, the MC voltage level was precisely set, considering the short circuit current. For a reduction in the MC voltage value for power system stability, the proposed scheme with varying $\mathrm{MC}$ voltage levels should be considered to determine the appropriate value.

Author Contributions: N.C. conceived and designed the research methodology, performed the system simulations, and wrote this paper. B.L. supervised the research, improved the system simulation, and made suggestions regarding this research. The other authors discussed and contributed to the writing of the paper.

Funding: This research received no external funding.

Acknowledgments: This work was supported by "Human Resources program in Energy Technology" of the Korea Institute of Energy Technology Evaluation and Planning (KETEP)-granted financial resource from the Ministry of Trade, Industry, and Energy, Republic of Korea (no. 20174030201820).

Conflicts of Interest: The authors declare no conflicts of interest.

\section{Appendix A}

Table A1. Characteristic of the KEPCO systems in Honam.

\begin{tabular}{lcc}
\hline \multicolumn{1}{c}{ System Characteristics } & Base Case & IBR Case \\
\hline Number of buses & 288 & 512 \\
Number of lines & 439 & 480 \\
Number of CSGs ${ }^{1}$ & 51 & 51 \\
Number of IBRs & - & 315 \\
Number of loads & 195 & 195 \\
Total power from generators & $8.8 \mathrm{GW}$ & $21.0 \mathrm{GW}$ \\
Total load & $11.0 \mathrm{GW}$ & $11.0 \mathrm{GW}$ \\
\hline
\end{tabular}

${ }^{1}$ CSGs: Conventional synchronous generators.

\section{References}

1. Nimpitiwan, N.; Heydt, G.T.; Ayyanar, R.; Suryanarayanan, S. Fault current contribution from synchronous machine and inverter based distributed generators. IEEE Trans. Power. Deliv. 2007, 22, 634-641. [CrossRef]

2. Green, T.C.; Prodanović, M. Control of inverter-based micro-grids. Elec. Power Syst. Res. 2007, 77, 1204-1213. [CrossRef]

3. Carrasco, J.M.; Franquelo, L.G.; Bialasiewicz, J.T.; Galvan, E.; PortilloGuisado, R.C.; Prats, M.A.M.; Leon, J.I.; Moreno-Alfonso, N. Power-Electronic Systems for the Grid Integration of Renewable Energy Sources: A Survey. IEEE Trans. Ind. Electron. 2006, 53, 1002-1016. [CrossRef]

4. IEEE/NERC Task Force on Short-Circuit and System Performance Impact of Inverter Based Generation. Impact of Inverter Based Generation on Bulk Power System Dynamics and Short-Circuit Performance. 2018. Available online: http:/ / resourcecenter.ieee-pes.org/pes/product/technical-publications/PES_TR_7-18_ 0068 (accessed on 17 September 2018).

5. Plet, C.A.; Graovac, M.; Green, T.C.; Iravani, R. Fault response of grid-connected inverter dominated networks. In Proceedings of the IEEE PES General Meeting, Minneapolis, MN, USA, 25-29 July 2010; pp. 1-8.

6. Barsch, J. Fault current contributions from wind plants. In Proceedings of the 2015 68th Annual Conference for Protective Relay Engineers, College Station, TX, USA, 30 March-2 April 2015; pp. 137-227.

7. Baran, M.E.; El-Markaby, I. Fault analysis on distribution feeders with distributed generators. IEEE Trans. Power Syst. 2005, 20, 1757-1764. [CrossRef] 
8. Barker, P.; DeMello, R. Determining the impact of DG on power systems radial distribution. In Proceedings of the 2000 Power Engineering Society Summer Meeting, Washington, DC, USA, 16-20 July 2000; pp. 1645-1656.

9. Keller, J.; Kroposki, B.D. Understanding fault characteristics of inverter-based distributed energy resources; National Renewable Energy Laboratory: 2010. Available online: http:/ / research.iaun.ac.ir/pd/bahador. fani/pdfs/UploadFile_9423.pdf (accessed on 16 November 2018).

10. IEEE. IEEE Standard for Interconnection and Interoperability of Distributed Energy Resources with Associated Electric Power Systems Interfaces. In IEEE Std 1547-2018 (Revision of IEEE Std 1547-2003), 2018. Available online: https://www.google.com/url?sa=t\&rct=j\&q=\&esrc=s\&source= web\&cd=3\&cad $=$ rja\&uact=8\&ved $=2$ ahUKEwiBm5OD58bgAhUEzLwKHfOsDLUQFjACegQICRAB\& url=https $\% 3 \mathrm{~A} \% 2 \mathrm{~F} \% 2$ Fieeexplore.ieee.org $\% 2 F i e l 7 \% 2 \mathrm{~F} 8332110 \% 2 \mathrm{~F} 8332111 \% 2 \mathrm{~F} 08332112 . p d f \& u s g=$ AOvVaw0YqjsUrXdUmTdTBE8kc2NF (accessed on 10 November 2018).

11. North America Electric Reliability Coporation (NERC). 1200 MW Fault Induced Solar Photovoltaic Resource Interruption Disturbance Report: June, 2017. Available online: https://www.nerc.com/pa/rrm/ea/ 1200_MW_Fault_Induced_Solar_Photovoltaic_Resource_/1200_MW_Fault_Induced_Solar_Photovoltaic_ Resource_Interruption_Final.pdf (accessed on 17 September 2018).

12. NERC. 900 MW Fault Induced Solar Photovoltaic Resource Interruption Disturbance Report; North America Electric Reliability Coporation (NERC): Feb, 2018. Available online: https://www.nerc.com/ pa/rrm/ea/October\%209\%202017\%20Canyon\%202\%20Fire\%20Disturbance\%20Report/900\%20MW\% 20Solar\%20Photovoltaic\%20Resource\%20Interruption\%20Disturbance\%20Report.pdf (accessed on 10 December 2018).

13. Heydt, G.T. Computer Analysis Methods for Power Systems; Stars in a Circle: Scottsdale, AZ, USA, 1996.

14. Kanellos, F.D.; Kabouris, J. Wind Farms Modeling for Short-Circuit Level Calculations in Large Power Systems. Ieee T Power Deliver 2009, 24, 1687-1695. [CrossRef]

15. Kennedy, J.; Ciufo, P.; Agalgaonkar, A. Fault approximation tool for grid-connected inverter-interfaced distributed generators. In Proceedings of the 2014 Australasian Universities Power Engineering Conference (AUPEC), Perth, Australia, 28 September-1 October 2014; pp. 1-6. Available online: https://pdfs. semanticscholar.org/e235/bf65e6a5b69056ac6959ac68ce982dd8a73f.pdf (accessed on 10 December 2018).

16. Boutsika, T.N.; Papathanassiou, S.A. Short-circuit calculations in networks with distributed generation. Elec. Power Syst. Res. 2008, 78, 1181-1191. [CrossRef]

17. Brucoli, M.; Green, T.C.; McDonald, J.D.F. Modelling and Analysis of Fault Behaviour of Inverter Microgrids to Aid Future Fault Detection. In Proceedings of the 2007 IEEE International Conference on System of Systems Engineering, San Antonio, TX, USA, 16-18 April 2007; pp. 1-6.

18. Al Tarabsheh, A.; Akmal, M.; Ghazal, M. Series Connected Photovoltaic Cells-Modelling and Analysis. Sustainability 2017, 9, 371. [CrossRef]

19. Liu, S.; Bi, T.; Liu, Y. Theoretical Analysis on the Short-Circuit Current of Inverter-Interfaced Renewable Energy Generators with Fault-Ride-Through Capability. Sustainability 2018, 10, 44. [CrossRef]

20. El-Naggar, A.; Erlich, I. Fault Current Contribution Analysis of Doubly Fed Induction Generator-Based Wind Turbines. IEEE Trans. Energ. Convers. 2015, 30, 874-882. [CrossRef]

21. The 8th Basic Plan for Long-Term Electricity Supply and Demand (2017-2031). Available online: $\quad$ https: / / www.google.com/url? sa=t\&rct=j\&q=\&esrc=s\&source=web\&cd=1\&cad= rja\&uact=8\&ved=2ahUKEwjF9eaC6cbgAhWKebwKHcJQAEgQFjAAegQIChAC\&url=https\% 3A\%2F\%2Fwww.kpx.or.kr\%2Fwww\%2FdownloadBbsFile.do\%3FatchmnflNo\%3D30051\&usg= AOvVaw0VKjAEyUNSWdhLkGLVFFob (accessed on 14 August 2018).

(C) 2019 by the authors. Licensee MDPI, Basel, Switzerland. This article is an open access article distributed under the terms and conditions of the Creative Commons Attribution (CC BY) license (http://creativecommons.org/licenses/by/4.0/). 